\title{
What doctors should call their patients
}

\author{
Michael Lavin University of Tennessee, USA
}

\section{Author's abstract}

The paper discusses the moral difficulties physicians encounter when determining the level of formality they will use when addressing their patients. It is argued that physicians ought not to use a patient's first name unless the patient also uses the physician's first name. In short, physicians and patients should always address each other with the same level of formality. It is argued that this is so even when patients invite physicians to address them informally.

The moral issues connected with naming are not unfamiliar. Take, for example, the case of Mrs Lucille Natkins. In 1982 she described what happened to her when she underwent a dilation and curettage as follows:

One visit and several phone calls later - all conducted on a cordial 'Dr Gold' and 'Mrs Natkins' basis surgery was scheduled and soon afterward I was wheeled into the operating room. As my vision blurred and my legs numbed, a voice cut through the anaesthetic haze. 'Hi, Lucille, this is Dr Gold!' Stupor turned to rage. 'You expletive, that's not the way it goes! It goes ' $\mathrm{Hi}$, Lucille, this is Jim' or ' $\mathrm{Hi}$, Mrs Natkins, this is Dr Gold' (1).

Mrs Natkins went on to voice her suspicion that $\mathrm{Dr}$ Gold had a dark agenda. For what purpose could his familiarity have served other than to underscore her 'lack of dignity and helplessness'? And although I doubt that he meant any such thing by his informality, the intensity of Mrs Natkins response puts the moral seriousness of the naming issue into relief. For at least some patients, physicians' identifying themselves by title and last name while calling patients by their first name is offensive.

If anybody suspects that Mrs Natkins is idiosyncratic in her naming preferences, evidence that she is not exists. In 1987 The fournal of the American Medical Association ran a piece titled 'Patient and house

\section{Key words}

First names; last names; formal address; informal address. officer attitudes on physician attire and etiquette' (2). 胥 Although its principal focus centred on how patients feel about what their physicians wear, it also touched $\vec{t}$ on what patients and doctors prefer to call each other. Of the patients surveyed, 18 per cent wanted their $\tilde{N}_{0}$ doctors to refer to them by their last name, while 40 per 0 cent preferred to hear their first name. Seventy-four per cent wanted to address their physicians formally, $\bar{\infty}$ that is, by name and title. Doctors strongly preferred $\mathbb{D}$ the formality of their titles: only three per cent of $\mathbb{D}$ physicians preferred to be called by their first name, 긍 while 65 per cent preferred to be called by their $\stackrel{\Phi}{-}$ surname and title. Moreover, only one per cent of $\overrightarrow{0}$ surveyed physicians claimed to use the first names of $\infty_{\infty}^{\infty}$ their patients. Unfortunately, the survey did not as patients whether their doctors in fact used formal informal address. The one per cent figure for informality is, however, suspiciously low. A 1984 study by Senger revealed that 25 per cent of the $\frac{\circ}{\Phi}$ psychiatrists he surveyed preferred, and evidently did, $\stackrel{\square}{\rightarrow}$ refer to their patients by first name (3). My informal $\overrightarrow{\bar{O}}$ headcounts also suggest that physicians do often 3 address their patients by first name. In any event, $\mathrm{I}$ believe the issue of doctor-patient address raises moral problems worth investigating. These problems are acutest when a doctor addresses his patients informally while expecting or encouraging formality in return.

I hope it is reasonably plain that the innocence of $\operatorname{Dr} \delta$ Gold's intentions did not mean that Mrs Natkins was wrong to take offence. A man may not realise, for음 example, that calling all women 'darling' is $>$ disrespectful. His breeding may even make it impossible for him to recognise idle love chat as N disrespectful; nevertheless, it is disrespectful. So the - issue at hand was whether first-naming patients is $\tilde{O}$ disrespectful when formal address is the anticipated N reply, not whether informality towards patients iso intended disrespectfully.

To get a better perspective on why addressing patients informally might be perceived as morally? undesirable behaviour, it helps to review the circumstances under which first-naming typically. occurs. First, friendly peers (equals - Ed.) use first ${ }^{\mathbb{D}}$ names. Second, social superiors are apt to refer to their social inferiors by their first name. Illustrative examples spring to mind. Friends use first names, as 
do colleagues on good terms. Adults, however, call children by their first name. That practice tends to extend itself to the service industries. The customer, $\mathrm{Mr}$ or Ms Superior, is invited to call the server Joe or Molly. In medicine inequalities in the formality of address appear to belong to this second class. The prestige of the physician encourages a genial informality towards at least some patients. If, then, informally addressing patients is disrespectful, one reason for that may be the effect it has of identifying the patient as in some way inferior to the doctor, an identification with potentially wide-ranging ramifications.

Of course once physicians realise that some patients object to being addressed by their first name, they have reason enough, in the absence of any compelling reasons to the contrary, for keeping their exchanges with patients formal. The previously cited JAMA study makes just that recommendation, stating that 'since a sizeable portion of the patient population would be offended by being addressed by their first names, the more formal approach would thus seem advisable unless the patient specifically requests otherwise' (2). The possibility exists, however, that this recommendation not only captures what the appropriate convention should be, given many patients' preference, but that it also captures a moral requirement; for if, as indeed seems to be the case, informally addressing patients tends to emphasise their status as the physicians' inferiors, that is a powerful moral reason to stop doing it. After all, doctors ought to have an eye for the patient's good. Various goods are endangered by a practice which subtly reinforces a patient's sense of inferiority. When one further considers that a patient's perception of him or herself as an inferior works to inhibit him from asserting his right to participate in treatment decisions, firstnaming patients may threaten, in a morally objectionable way, the therapeutic alliance. Informality imposes moral costs. But are there compensating benefits?

Some clinicians do not think the costs of firstnaming patients are too high. The benefits, the story goes, repay the costs. The appropriate, empathic use of names is taken to be part of the clinical art. If a physician awaits an invitation to use a patient's first name, she may lose an opportunity to set the clinical agenda. Judiciously elected informality permits astute physicians to secure medically useful power. Given that good medicine consists in not only persuading but in bullying and cajoling patients to overcome their weak wills, a clinician's seizing a boss's power may be in the best interest of some patients. If I eat, drink, and smoke too much, odds are I will need help in moderating my appetites. My doctor's slyly grabbing superior power increases the likelihood that I will moderate them. For me to grant my physician this power would not work as well as having her just take it. In some cases, then, a clinician's informality may indicate no more than a preference for good doctoring over good manners. And if a patient does take offence, he can always complain. Such complaints, on the present view, arise from a mistake in clinical judgement. Even though that mistake causes the patient a moral injury through its lack of respect, it is an injury whose cause resides in clinical judgement. Senger's previously cited paper quoted a psychiatrist to illustrate the therapeutic use of naming.

'I use the first name initially to deliberately foster the parent child transference. But I resolve this in the end by eventually requesting the patient to call me by my first name also and work through the resistance to doing this. Thus we end on an adult to adult basis' (4).

Although there is little evidence that the use of informality to further clinical ends is common, this testimony would suggest that the practice is more common than might be supposed. So, the present defence of informal address recognises its moral costs, but believes them sometimes to be insufficiently weighty in relation to the therapeutic benefits.

Responding to this argument is not easy. Unfortunately, for philosophers, it is not a matter that can be settled with armchair sociology. One would have to know, for example, whether informality truly does make a positive contribution to therapeutic ends after one allows for the potential moral risks. In addition the argument requires what are bound to be extremely controversial calculations about the appropriate weight to assign to an injury to a person's self-respect. These technical difficulties may be surmountable (although the history of utilitarianism does not justify optimism), but it is rash to assume that the expected benefits of informality outweigh the expected risks without the benefit of evidence. Hence the recommendation of the JAMA study stands: Don't call patients by their first name without an invitation. And even if some patients are offended when called by their last name, the likelihood of that doing irreparable damage to the therapeutic relationship would appear to be slight, especially given what is presently reasonable to believe about patient preferences in regard to naming.

What, though, should physicians do when a patient invites them to use his first name? Undoubtedly the common sense answer would be to accept the invitation, which is also the policy recommended in the JAMA study. I, however, believe that a good case can be made for rejecting informality unless the physician also insists that the patient respond in kind. I will sketch two arguments in support of my position. First, I shall explain why I think that unreciprocated informality towards patients inhibits their ability to make adult choices. Second, I shall argue that informal address undermines morally desirable commitments to egalitarian practices.

If unreciprocated informality towards patients inhibits their capacity for adult choice, one reason for objecting to it is already familiar. Assuming the role of an inferior in a social relationship damages the capacity persons have to choose for themselves. Patients who 
wittingly or unwittingly compromise their power of choice might cheat themselves out of having as good care from their physicians as they might have. Although I think the trend towards increasing patient participation in treatment decisions could underwrite this objection, I do not think enough is known to tell whether treatment would be impaired; consequently, I note, but will not rely on the claim that it is unreciprocated informality that truly damages health care. Rather, I maintain that even if research eventually revealed that patients' retaining their fullest possible range of rational choice puts them at somewhat greater health risk (it verges on fatuous to suppose the risk would be vastly greater), nothing should be done or permitted in regard to naming which compromises a patient's agency. For it is by conscientiously preserving patients' range of choice that physicians exhibit respect for their patients as morally considerable beings.

To appreciate the respectfulness of insisting on the preservation of a person's full agency, the following example may help. Suppose I invite a co-worker, with whom I am presently on a last name basis, to call me by my first name. What could that invitation in that context mean? First off, it may indicate a desire for a friendlier relationship. But if that is what is desired, the friendly overture should be reciprocated or rejected. On the other hand, I may well be making a show of my recognition of my co-worker's higher status. If I do so in the hope of currying favour, I am a toady. If I do so out of a desire to formalise her superiority, I am servile. In either case, it would appear that I am putting her in a position to exercise control over me that would not, in the ordinary course of events, be considered legitimate. I have tacitly given a sort of permission for her to arrogate to herself some of my decisional options. Since it is ordinarily thought to be a bad thing for a person to make another his master, that reduction in autonomy requires justification. And even if I claim to reserve the right to review what, say, my physician may have me do, I do not, if I have established differences in the formality of address, perform my review as an equal. My abdication of equal formality in address testifies to my perception that I am not my physician's equal. It requires more defence than I will offer here, but I believe the most plausible hypothesis for a patient inviting informality towards himself is that he covertly wishes to establish his dependency and servility towards the physician. Physicians, if I am right, should oppose such infantilising desires, and strive to protect and foster their patients' capacity to participate in the therapeutic relationship as less informed equals on their own treatment team. In brief, physicians should fight to keep their patients adults.

The last argument against first-naming is straightforward, and reinforces the previous? considerations in favour of equality. Egalitarian $\underset{\overrightarrow{\mathrm{S}}}{\overrightarrow{\mathrm{f}}}$ treatment of human beings is a good thing. Over the past several decades, moral opinion has gravitated towards the desirability of eliminating needless inequalities. Given my previous arguments, it is not plausible to claim that physicians need to preserve inequalities in address. Undoubtedly there are the $\infty$ comforts of familiarity in observing longstanding $\vec{O}$ traditions which leave the physician's superior position $\vec{\overrightarrow{ }}$ intact. Still, medicine needs moral vision. Kant's $\vec{\omega}$ deeply moving conception of the moral community as a kingdom of ends is worth recalling. For Kant the moral world is inhabited by free and rational agents $\vec{A}$ who are equally valuable in themselves. Unfortunately $\dot{\omega}$ the contingencies of life may at times blind moral $\vec{N}$ beings to the equal distribution of moral worth. $\bullet$

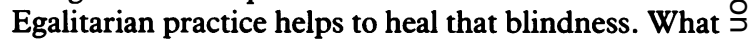
is more, my claim that keeping address at the same $\vec{\sim}$ level of formality is a way of revering the moral equality $\mathbb{D}$ of persons is susceptible to a test. Suppose, for the $\frac{\vec{D}}{\mathbb{D}}$ moment, that this paper's previous arguments about costs succeeded. How might you tell how you feel $\mathbb{D}$ about the issues of equality and respect? Represent vividly to yourself another human being needless $B$ addressing you by your first name, while wishing y

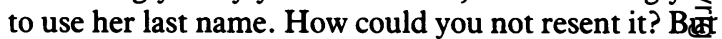
perhaps you want her to call you so. If there is no need what reason could you have? Inequalities are not the stuff of friendship or love. And what good reasons could a physician have for expecting formality while $\mathscr{\complement}$ returning informality or for acceding to your request $\overrightarrow{\overrightarrow{0}}$ without reciprocating? To ask these questions should be to answer them: None.

Michael Lavin BA MA PhD is Assistant Professor in the Department of Philosophy, University of Tennessee, $\dot{0}$ Knoxville, TN 37996-0480, USA.

\section{References}

(1) Natkins L G. 'Hi, Lucille, This is Dr Gold!' Fournal of the $\frac{\text { D }}{2}$ American Medical Association 1982; 247: 2415.

(2) Dunn J L, Lee T H, Percelay J M, et al: Patient and house $\widetilde{O}$ officer attitudes on physician attire and etiquette. Fournal of the American Medical Association 1987; 257: 65-68.

(3) Senger H. First name or last? Addressing the patient in psychotherapy. Comprehensive psychiatry 1984; $25: 38-42$.

(4) See reference (3): 42 . 